\title{
KETERKAITAN KURS DAN TINGKAT BUNGA
}

\author{
Edy Rahmantyo Tarsilohadi \\ Fakultas Ekonomi Universitas Bengkulu
}

\begin{abstract}
The deep depreciation of the Rupiah from August 1997 through 1998 poses a big problem for domestic economic. Because the Indonesia economic faced with the international trade deficit and the balance of capital surplus, has given rise to the depreciation of Rupiah. At the same time, the banking sector has been higher interest rates. Examination of the data indicates causal linkage between the exchange rate of rupiah and the interest rate, vice versa. This result reflects the weakness of the real and monetary sectors in Indonesia. To avoid the failure economic, will need the contribution monetary and others policies make to that environment are critical.
\end{abstract}

Keywords: foreign exchange, interest rate, causality

\section{PENDAHULUAN}

Globalisasi atau keterbukaan hubungan perekonomian antar negara pada hakikatnya adalah merupakan tuntutan alamiah setiap manusia, karena setiap manusia memiliki hak dan keinginan untuk bersosialisasi dan berasimilasi dengan orang lain, atau pengertian ini dapat diperluas menjadi bangsa atau negara.

Pada masa sekarang, globalisasi sudah menjadi keharusan, guna menjalin perdagangan dan hubungan ekonomi lainnya antar negara. Hal ini dikarenakan di satu sisi terdapat kelangkaan sumberdaya, produksi barang dan jasa ataupun modal di suatu negara sedang di sisi lain terdapatnya surplus di negara lain, sehingga dibutuhkan pertukaran/perdagangan untuk saling memenuhi kebutuhan setiap negara.

Kemajuan teknologi dan informasi yang demikian pesat, berdampak pula terhadap hubungan perekonomian antar negara, baik sektor riil maupun moneter. Khususnya di sektor moneter, berdampak iklim ekonomi internasional menjurus terjadinya suatu integrasi pasar keuangan, kondisi pasar keuangan suatu negara saling terkait dengan situasi pasar internasional. Hal ini membawa implikasi yang sangat penting dan kompleks bagi kebijakan perekonomian suatu negara khususnya di sektor moneter. Dalam era 60 'an pembahasan kebijakan moneter untuk mengantisipasi situasi ini sudah demikian rumitnya.(Friedman, 1968). Demikian pula yang terjadi di Indonesia, situasi iklim moneter internasional mempengaruihi perekonomian dalam negeri. Sehingga kebijakan pengendalian nilai uang tidak bisa hanya dilakukan secara parsial, tetapi harus dilakukan secara bersama. Sebagai contoh kebijakan inflasi, tingkat bunga dan kurs 
yang selama ini dilakukan secara terpisah .Tetapi dengan adanya krisis moneter yang melanda negeri ini pertengahan tahun 1997, kebijakan moneter yang dilakukan secara parsial tidak membawa hasil yang memuaskan. Bahkan Bank Indonesia yang bertugas membuat kebijakan tersebut nampak kehilangan kepercayaan untuk mengatasinya (Boediono, 1998).

Krisis moneter di Indonesia, ditandai adanya fenomena jatuhnya kurs Rupiah yang dimulai akhir bulan Agustus 1997, kemudian diikuti juga dengan membubung tingginya suku bunga dalam negeri yang berakibat merontokkan perekonomian negeri ini.

Atas dasar pengalaman krisis moneter ini, menarik perhatian yang serius kiranya perlu penelahan keterkaitan antar variabel yang mendalam.

Dengan adanya krisis moneter yang melanda Indonesia, membuka cakrawala betapa kompleksnya permasalahan moneter di negeri . ini. Sungguhpun demikian, presentasi yang sederhana ini dimaksudkan sebagai upaya mencari benang merah permasalahannya. Penelitian ini dilakukan untuk mengkaji keterkaitan hubungan antara nilai kurs Rupiah dan tingkat suku bunga dalam negeri, dengan tujuan:

Pertama, mencari bentuk pola hubungan antara nilai kurs rupiah dan tingkat bunga domestik.

Kedua, dengan telah diketemukan pola tersebut, kemudian dirumuskan faktor-faktor penyebabnya, sehingga akhirnya dapat dicari alternatif kebijakan untuk masa yang akan datang.

\section{TINJAUAN TEORI}

\section{Tingkat Bunga}

Pengertian sederhana dari tingkat bunga, yaitu "harga" keseimbangan pasar antara penawaran dan permintaan dana yang digunakan untuk pembiayaan investasi. Harga tersebut adalah merupakan balas jasa bagi pemiliknya yang bersedia untuk meminjamkan modalnya, atau sebaliknya merupakan jasa yang selayaknya dibayar oleh para peminjam dana. Tingkat bunga identik dengan "harga dana" yang besarnya berfluktuasi sesuai dengan kondisi keseimbangan pasarnya, yaitu mengikuti hukum permintaan dan penawaran. Permintaan dana adalah pencerminan kebutuhan dana untuk pembiayaan investasi yang dilakukan baik oleh individu rumah tangga, swasta ataupun pemerintah. Sedangkan penawaran dana adalah merupakan tabungan yang berasal dari individu, swasta ataupun pemerintah. Dengan demikian naik turunnya tingkat bunga dikarenakan oleh ketidakseimbangan antara dana tabungan dan investasi dalam negeri. Di samping itu, ketidakseimbangan dana di atas, dapat juga disebabkan adanya defisit anggaran pemerintah. Dengan demikian apabila untuk mencukupi kedua kebutuhan dana dalam negeri di atas, dilakukan dengan mengimpor modal asing (capita inflow), maka akan berpengaruh terhadap tingkat kurs. Juga sebaliknya, bila terjadi capital outflow, misalnya untuk membayar kembali dana modal asing, maka juga berpengaruh terhadap tingkat kurs. (Dornbusch, 1983)

\section{Kurs}

Nilai kurs mata uang suatu negara adalah "harga" mata uang negara tersebut terhadap mata uang asing. Sedangkan "harga" 
ditentukan oleh adanya keseimbangan antara permintaan dan penawaran yang terjadi di pasar. Dengan demikian, kurs mata uang suatu negara sebenarnya adalah harga keseimbangan antara permintaan dan penawaran mata uang negara tersebut di pasar uang, baik dalam negeri ataupun internasional. Adapun fluktuasi nilai kurs dapat ditelaah melalui indikator dari Neraca Pembayaran Internasional, sebagai berikut: (Mussa, 1974, Frenkel, 1976 dan Mundell, 1963)

\section{a. Neraca Perdagangan Barang \& Jasa}

Ekspor Barang dan Jasa (X) dari sisi moneter merupakan faktor yang menunjukkan 'penawaran' mata uang asing atau sebaliknya merupakan "permintaan" mata uang dalam negeri di pasar uang, sebagai akibat adanya transaksi perdagangan keluar negeri yang berupa penerimaan valuta asing.

Impor Barang dan Jasa (M) dari sisi moneter adalah merupakan "permintaan" mata uang asing di pasar uang guna pembayaran transaksi kepada pihak luar negeri atau sebaliknya merupakan "penawaran" mata uang dalam negeri di pasar uang. Dengan demikian, bila suatu negara mengalami surplus dalam Neraca Perdagangan $(X>M)$, maka akan terjadi kecenderungan peningkatan nilai kurs mata uang negara tersebut (Apresiasi/Evaluasi). Hal ini terjadi karena terdapat kecenderungan peningkatan permintaan mata uang negara tersebut lebih besar daripada penawarannya di pasar uang. Demikian juga sebaliknya, bila suatu negara mengalami deficit neraca perdagangannya $(M>X)$, maka akan terdapat kecenderungan penurunan nilai kurs mata uangnya (Depresiasi/Devaluasi), karena dalam pasar uang terdapat kecenderungan penawaran mata uang negara tersebut lebih besar daripada permintaannya. (Abell, 1990)

\section{b. Neraca Modal}

Analisa moneter neraca modal mempunyai fenomena yang berlawanan dengan neraca perdagangan. Ekspor Modal bentuknya dapat berupa penanaman modal domestik ke luar negeri, pelarian modal keluar negeri, pembayaran hutang luar negeri baik berupa angsuran pokok ataupun pembayaran bunga. Dengan demikian fenomena ekspor modal adalah merupakan penawaran mata uang dalam negeri di pasar uang atau sebaliknya merupakan permintaan akan mata uang asing.

Impor Modal adalah masuknya dana luar negeri, yang bentuknya antara lain berupa penanaman modal asing atau hutang dari luar negeri. Fenomena moneter ini merupakan permintaan akan mata uang dalam negeri atau sebaliknya merupakan penawaran mata uang asing.(Evans, 1986)

Dengan demikian, bila suatu negara mengalami surplus neraca modal, maka akan terdapat kecenderungan penurunan nilai kurs mata uangnya (Depresiasi/Devaluasi). Hal ini dikarenakan adanya kecenderungan penawaran mata uang dalam negeri lebih besar dari permintaannya di pasar uang. Atau sebaliknya, bila suatu negara mengalami deficit neraca modalnya, maka kurs mata uang negara tersebut akan mengalami kecenderungan yang meningkat (Apresiasi/ Evaluasi). (Hutchinson \& Pigott, 1984)

\section{METODE PENELITIAN}

Penelitian ini menggunakan data sekunder dari Bank Indonesia, yaitu tingkat bunga dan kurs rupiah terhadap dollar AS dari Januari 1996 s/d Agustus 2004. Adapun karena data 
yang digunakan bersifat time series (urut waktu), dimana sering terdapat data yang tidak stasioner yang menyebabkan hasil regresi yang bersifat lancung (spurious), maka dalam penelitian ini dilakukan tahapan analisis sebagai berikut:

1. Uji Stasioneritas terhadap variabel Tingkat Bunga dan Kurs, dengan menggunakan uji Root Augmented Dickey-Fuller (Arief, 1993; Gujarati, 2003)

2. Apabila ternyata kedua variabel adalah stasioner, maka dilanjutkan ke uji kausalitas Granger pada data asli. (Granger, 1969; Gujarati, 2003)

3. Hanya bila salah satu dari kedua variabel atau keduanya tidak stasioner, maka harus distasionerkan terlebih dahulu dan jika kedua variabel tidak stasioner, maka akan dilakukan pengujian untuk mengetahui apakah kedua variabel terkointegrasi atau tidak. Variabel yang terkointegrasi adalah variabel yang masing-masing memiliki pola trend yang sama. Oleh karenanya ketika variabel tersebut diregresikan, maka trend masing-masing variabel akan saling menghapuskan. Atau adakalanya dua variabel mempunyai pola random walk, tetapi kombinasi linear antara kedua variabel bersifat stasioner (Arief, 1993; Gujarati, 2003). Apabila kedua variabel ternyata terkointegrasi, maka dilanjutkan ke uji kausalitas Granger pada data asli.

4. Apabila kedua variabel tidak terkointegrasi, maka data yang tidak stasioner harus distasionerkan lebih dulu dengan cara differencing. Baru kemudian dilanjutkan ke uji kausalitas Granger dari data yang telah stasioner.

\section{A. STASIONERITAS DAN UJI STASIONERITAS}

Suatu data time series (urut waktu) dikatakan stasioner, apabila memenuhi syarat-syarat sebagai berikut :(Gujarati, 2003)

$$
\begin{aligned}
\text { Rata-rata : } E\left(Y_{t}\right)=\mu, & \begin{aligned}
\text { rata-ratanya adalah } \\
\text { konstan }
\end{aligned} \\
\text { Variance : } \operatorname{Var}\left(Y_{t}\right)= & E\left[\left(Y_{t}-\mu\right)^{2}\right]=\sigma^{2}, \\
& \text { variancenya adalah } \\
& \text { konstan }
\end{aligned}
$$
Variance : $\operatorname{Var}\left(Y_{t}\right)=E\left[\left(Y_{t}-\mu\right){ }^{2}\right]=\sigma^{2}$, variancenya adalah konstan

Covariance : $k=E\left[\left(Y_{t}-\mu\right)\left(Y_{t}+k-\mu\right)\right]$

Covariance antara dua periode waktu bergantung hanya pada jarak waktu antara dua periode tersebut, dan tidak bergantung pada periode waktu dimana covariance dihitung.Dalam data urut waktu yang stasioner, pada prinsipnya tidak ada gerakan trend yang bersifat sistematik, artinya perkembangan nilai variabel diakibatkan hanya oleh faktor random yang bersifat stokastik. Penelitian ini, untuk pengujian stasioneritas yaitu menggunakan uji unit root Augmented Dickey-Fuller (ADF). Adapun formulasinya sebagai berikut :

- Variabel tingkat bunga (TB)

$$
\begin{aligned}
& \Delta \mathrm{TB}_{\mathrm{t}}=\beta_{1}+\beta_{2} \mathrm{t}+\delta \mathrm{TB}_{\mathrm{t}-1}+\alpha_{\mathrm{i}} \sum_{\mathrm{i}=1}^{k} \Delta \mathrm{TB}_{\mathrm{t}-1}+\mu_{\mathrm{t}} \\
& \Delta \mathrm{TB}_{\mathrm{t}}=\beta_{1}+\delta \mathrm{TB}_{\mathrm{t}-1}+\alpha_{\mathrm{i}} \sum_{\mathrm{i}=1}^{k} \Delta \mathrm{TB}_{\mathrm{t}-1}+\mu_{\mathrm{t}} \\
& \Delta \mathrm{TB}_{\mathrm{t}}=\delta \mathrm{TB}_{\mathrm{t}-1}+\alpha_{\mathrm{i}} \sum_{\mathrm{i}=1}^{k} \Delta \mathrm{TB}_{\mathrm{t}-1}+\mu_{\mathrm{t}}
\end{aligned}
$$

- Variabel kurs (K)

$$
\begin{aligned}
& \Delta \mathrm{K}_{\mathrm{t}}=\mathrm{B}_{1}+B_{2} \mathrm{t}+\delta \mathrm{K}_{\mathrm{t}-1}+\alpha_{\mathrm{i}} \sum_{\mathrm{i}=1}^{k} \Delta \mathrm{K}_{\mathrm{t}-1}+\mu_{\mathrm{t}} \\
& \Delta \mathrm{K}_{\mathrm{t}}=\mathrm{B}_{1}+\delta \mathrm{K}_{\mathrm{t}-1}+\alpha_{\mathrm{i}} \sum_{\mathrm{i}=1}^{k} \Delta \mathrm{K}_{\mathrm{t}-1}+\mu_{\mathrm{t}}
\end{aligned}
$$




$$
\Delta \mathrm{K}_{\mathrm{t}}=\delta \mathrm{K}_{\mathrm{t}-1}+\alpha_{\mathrm{i}} \sum_{\mathrm{i}=1}^{k} \Delta \mathrm{K}_{\mathrm{t}-1}+\mu_{\mathrm{t}}
$$

\section{B. UJI KOINTEGRASI}

Berdasar metode Engle\& Granger (Gujarati 2003), kointegrasi antara variabel Tingkat Bunga dan Kurs yaitu dengan menghitung residu dari regresi kedua varibel tersebut, kemudian dilakukan uji Root Augmented Dickey-Fuller terhadap data residu tersebut.

Adapun formulasi pengujian, sebagai berikut:

$$
\begin{aligned}
& \Delta \mathrm{U}_{\mathrm{t}}=\beta_{1}+\beta_{2} \mathrm{t}+\delta \mathrm{U}_{\mathrm{t}-1}+\alpha_{\mathrm{i}} \sum_{\mathrm{i}=1}^{k} \Delta \mathrm{U}_{\mathrm{t}-1}+\mu_{\mathrm{t}} \\
& \Delta \mathrm{U}_{\mathrm{t}}=\beta_{1}+\delta \mathrm{U}_{\mathrm{t}-1}+\alpha_{\mathrm{i}} \sum_{\mathrm{i}=1}^{k} \Delta \mathrm{U}_{\mathrm{t}-1}+\mu_{\mathrm{t}} \\
& \Delta \mathrm{U}_{\mathrm{t}}=\delta \mathrm{U}_{\mathrm{t}-1}+\alpha_{\mathrm{i}} \sum_{\mathrm{i}=1}^{k} \Delta \mathrm{U}_{\mathrm{t}-1}+\mu_{\mathrm{t}}
\end{aligned}
$$

$\mathrm{U}$ adalah residu dari regresi antara Tingkat Bunga dan Kurs.

\section{UJI KAUSALITAS GRANGER (Granger, 1969; Gujarati, 2003)}

Formulasi regresi dari penelitian ini adalah sebagai berikut:

$$
\mathrm{TB}_{\mathrm{t}}=\sum_{\mathrm{i}=1}^{\mathrm{n}} a_{\mathrm{i}} \mathrm{K}_{\mathrm{t}-\mathrm{i}}+\sum_{j=1}^{\mathrm{n}} b_{\mathrm{j}} \mathrm{TB}_{\mathrm{t}-\mathrm{j}}+\mu_{\mathrm{t}}(\mathrm{I})
$$

$$
\mathrm{K}_{\mathrm{t}}=\sum_{\mathrm{i}=1}^{\mathrm{n}} c_{\mathrm{i}} \mathrm{TB}_{\mathrm{t}-\mathrm{i}}+\sum_{\mathrm{j}=1}^{\mathrm{n}} d_{\mathrm{j}} \mathrm{K}_{\mathrm{t}-\mathrm{j}}+\mathrm{v}_{\mathrm{t}} \text { (II) }
$$

Ada 4 kemungkinan hubungan dari hasil uji ini:

1. Terdapat hubungan kausalitas satu arah antara Tingkat Bunga terhadap Kurs, yaitu jika:

$$
\sum_{j=1}^{n} b_{j} \neq 0 \text { dan } \sum_{j=1}^{n} d_{j}=0
$$

2. Terdapat hubungan kausalitas satu arah antara Kurs terhadap Tingkat Bunga, yaitu jika:

$$
\sum_{j=1}^{n} b_{j}=0 \text { dan } \sum_{j=1}^{n} d_{j} \neq 0
$$

3. Terdapat hubungan kausalitas dua arah antara Kurs terhadap Tingkat Bunga atau sebaliknya, yaitu jika:

$$
\sum_{j=1}^{n} b_{j} \neq 0 \text { dan } \sum_{j=1}^{n} d_{j} \neq 0
$$

\begin{tabular}{|c|c|c|c|}
\hline \multirow[t]{3}{*}{ ADF Test Statistic } & -1.854363 & $1 \%$ Critical Value* & -4.0540 \\
\hline & & $5 \%$ Critical Value & -3.4557 \\
\hline & & $10 \%$ Critical Value & -3.1534 \\
\hline
\end{tabular}

4. Tidak terdapat hubungan kausalitas antara kedua variabel Kurs dan Tingkat Bunga, jika:

$$
\sum_{j=1}^{n} b_{j}=0 \text { dan } \sum_{j=1}^{n} d_{j}=0
$$

\section{HASIL PENELITIAN}

\section{Uji Stasioneritas Tingkat Bunga}

Hasil di bawah ini yaitu telah memenuhi semua persyaratan dengan Akaike Info Criterion yang minimum. 
*MacKinnon critical values for rejection of hypothesis of a unit root.

Augmented Dickey-Fuller Test Equation

Dependent Variable: D(TBUNGA)

Method: Least Squares

Date: 05/24/05 Time: 07:17

Sample(adjusted): 1996:07 2004:08

Included observations: 98 after adjusting endpoints

\begin{tabular}{crccc}
\hline \hline Variable & Coefficient & Std. Error & t-Statistic & Prob. \\
\hline \hline TBUNGA(-1) & -0.069536 & 0.037499 & -1.854363 & 0.0670 \\
D(TBUNGA(-1)) & -0.260110 & 0.104976 & -2.477789 & 0.0151 \\
D(TBUNGA(-2)) & 0.041267 & 0.108184 & 0.381453 & 0.7038 \\
D(TBUNGA(-3)) & 0.098816 & 0.108202 & 0.913260 & 0.3635 \\
D(TBUNGA(-4)) & 0.137893 & 0.108711 & 1.268438 & 0.2079 \\
D(TBUNGA(-5)) & 0.017536 & 0.104581 & 0.167676 & 0.8672 \\
C & 2.000641 & 0.991843 & 2.017094 & 0.0467 \\
@TREND(1996:01) & -0.013559 & 0.007103 & -1.909077 & 0.0594 \\
\hline \hline R-squared & 0.139711 & Mean dependent var & -0.073776 \\
Adjusted R-squared & 0.072800 & S.D. dependent var & 1.720474 \\
S.E. of regression & 1.656666 & Akaike info criterion & 3.925598 \\
Sum squared resid & 247.0087 & Schwarz criterion & & 4.136616 \\
Log likelihood & -184.3543 & F-statistic & & 2.087999 \\
Durbin-Watson stat & 2.008960 & Prob(F-statistic) & 0.052764 \\
\hline \hline
\end{tabular}

- Hasil pengujian unit root Augmented Dickey-Fuller $(A D F)$ atas data variabel Tingkat Bunga, bahwa data Tingkat Bunga tidak stasioner.

\section{Uji Stasioneritas Kurs}

Hasil di bawah ini yaitu telah memenuhi semua persyaratan dengan Akaike Info Criterion yang minimum.

\begin{tabular}{llll}
\hline ADF Test Statistic & -1.973080 & $1 \%$ Critical Value $^{*}$ & -3.4959 \\
& & $5 \%$ Critical Value & -2.8900 \\
& $10 \%$ Critical Value & -2.5818 \\
\hline
\end{tabular}

"MacKinnon critical values for rejection of hypothesis of a unit root.

Augmented Dickey-Fuller Test Equation

Dependent Variable: D(KURS)

Method: Least Squares

Date: 05/24/05 Time: 08:32

Sample(adjusted): 1996:04 2004:08

Included observations: 101 after adjusting endpoints

\begin{tabular}{ccccr}
\hline \hline Variable & Coefficient & Std. Error & t-Statistic & Prob. \\
\hline KURS(-1) & -0.073042 & 0.037019 & -1.973080 & 0.0513
\end{tabular}




\begin{tabular}{lrrrr}
\multicolumn{1}{l}{ D(KURS(-1)) } & -0.086577 & 0.098936 & -0.875079 & 0.3837 \\
\multicolumn{1}{c}{ D(KURS(-2)) } & -0.168969 & 0.098526 & -1.714972 & 0.0895 \\
\multicolumn{1}{c}{ C } & 652.5322 & \multicolumn{1}{c}{304.8006} & 2.140850 & 0.0348 \\
\hline \hline R-squared & 0.083758 & Mean dependent var & 69.20792 \\
Adjusted R-squared & 0.055420 & S.D. dependent var & 1121.406 \\
S.E. of regression & 1089.889 & Akaike info criterion & 16.86434 \\
Sum squared resid & $1.15 E+08$ & Schwarz criterion & 16.96791 \\
Log likelihood & -847.6490 & F-statistic & 2.955729 \\
Durbin-Watson stat & 1.991895 & Prob(F-statistic) & 0.036267 \\
\hline \hline
\end{tabular}

- Hasil pengujian unit root Augmented Dickey-Fuller (ADF) atas data variabel Kurs, bahwa data Kurs tidak stasioner.

\section{Uji Kointegrasi antara Kurs \& Tingkat Bunga}

Hasil di bawah ini yaitu telah memenuhi semua persyaratan dengan Akaike Info Criterion yang minimum.

\begin{tabular}{llll}
\hline ADF Test Statistic & \multirow{2}{*}{-2.259555} & $1 \%$ Critical Value $^{*}$ & -2.5862 \\
& & $5 \%$ Critical Value & -1.9432 \\
& $10 \%$ Critical Value & -1.6174 \\
\hline
\end{tabular}

*Mackinnon critical values for rejection of hypothesis of a unit root.

Augmented Dickey-Fuller Test Equation

Dependent Variable: $D(U)$

Method: Least Squares

Date: 05/24/05 Time: 07:13

Sample(adjusted): 1996:04 2004:08

Included observations: 101 after adjusting endpoints

\begin{tabular}{llllr}
\hline \multicolumn{1}{c}{ Variable } & Coefficient & Std. Error & t-Statistic & Prob. \\
\hline U(-1) & -0.133764 & 0.059199 & -2.259555 & 0.0261 \\
$D(U(-1))$ & -0.353347 & 0.102004 & -3.464045 & 0.0008 \\
$\mathrm{D}(U(-2))$ & -0.175892 & 0.097933 & -1.796038 & 0.0756 \\
\hline \hline R-squared & 0.206604 & Mean dependent var & 73.57404 \\
Adjusted R-squared & 0.190412 & S.D. dependent var & 1844.605 \\
S.E. of regression & 1659.722 & Akaike info criterion & 17.69594 \\
Sum squared resid & $2.70 \mathrm{E}+08$ & Schwarz criterion & 17.77362 \\
Log likelihood & -890.6450 & F-statistic & 12.75983 \\
Durbin-Watson stat & 2.022521 & Prob(F-statistic) & 0.000012 \\
\hline \hline
\end{tabular}

- Hasil pengujian unit root Augmented Dickey-Fuller $(A D F)$ atas data residu dari fungsi antara Kurs dan Tingkat Bunga, menunjukkan data yang stasioner. Dengan demikian, hasil pengujian kointegrasi Engle \& Granger (Gujarati, 2003) menunjukkan bahwa data variabel Kurs dan Tingkat Bunga terdapat kointegrasi. 


\section{Uji Kausalitas Granger antara Tingkat Bunga \& Kurs}

Pairwise Granger Causality Tests

Date: 05/24/05 Time: 08:14

Sample: 1996:01 2004:08

Lags: 5

\begin{tabular}{llll}
\hline \hline Null Hypothesis: & Obs & F-Statistic & Probability \\
\hline \hline TBUNGA does not Granger Cause KURS & 99 & 10.7186 & $4.6 \mathrm{E}-08$ \\
KURS does not Granger Cause TBUNGA & & 8.30647 & $1.8 \mathrm{E}-06$ \\
\hline
\end{tabular}

Pairwise Granger Causality Tests

Date: 05/24/05 Time: 08:34

Sample: 1996:01 2004:08

Lags: 6

\begin{tabular}{llll}
\hline \hline Null Hypothesis: & Obs & F-Statistic & Probability \\
\hline \hline TBUNGA does not Granger Cause KURS & 98 & 8.26788 & $4.7 \mathrm{E}-07$ \\
KURS does not Granger Cause TBUNGA & & 6.87734 & $5.6 \mathrm{E}-06$ \\
\hline \hline
\end{tabular}

Pairwise Granger Causality Tests

Date: 05/24/05 Time: 08:35

Sample: 1996:01 2004:08

Lags: 12

\begin{tabular}{llll}
\hline Null Hypothesis: & Obs & F-Statistic & Probability \\
\hline \hline TBUNGA does not Granger Cause KURS & 92 & 5.20451 & $4.3 \mathrm{E}-06$ \\
KURS does not Granger Cause TBUNGA & & 8.09336 & $4.0 \mathrm{E}-09$ \\
\hline \hline
\end{tabular}

Pairwise Granger Causality Tests

Date: 05/24/05 Time: 08:40

Sample: 1996:01 2004:08

Lags: 24

\begin{tabular}{llll}
\hline \hline Null Hypothesis: & Obs & F-Statistic & Probability \\
\hline \hline TBUNGA does not Granger Cause KURS & 80 & 5.25307 & $1.3 \mathrm{E}-05$ \\
KURS does not Granger Cause TBUNGA & & 9.02878 & $2.6 \mathrm{E}-08$ \\
\hline \hline
\end{tabular}

- Hasil pengujian kausalitas Granger antara Tingkat Bunga \& Kurs, menunjukkan hubungan dua arah dari kedua variabel tersebut yaitu mulai lag 5 sampai dengan 24.

\section{PEMBAHASAN}

Pengujian kausalitas data bulan Januari 1996 s/d Agustus 2004 antara Kurs Rupiah terhadap Dollar US dengan Tingkat Bunga, menunjukkan hubungan dua arah yaitu Kurs mempengaruhi Tingkat Bunga dan sebaliknya Tingkat Bunga mempengaruhi Kurs.
Hasil ini menggambarkan kondisi perekonomian Indonesia yang sangat memprihatinkan dalam era globalisasi perekonomian dunia, dimana persaingan hanya dimenangkan oleh negara dengan pondasi ekonomi yang kuat.

Jatuhnya nilai mata uang negara-negara ASEAN pertengahan tahun 1997, demikian 
pula rupiah, sebenarnya secara teori merupakan momen yang sangat menguntungkan untuk meningkatkan ekspor serta menekan impor barang dan jasa. Tetapi kenyataan yang terjadi justru kondisi perekonomian mengalami keadaan yang sebaliknya, dimana rupiah mengalami depresiasi yang semakin lama semakin besar. Pengkajian yang lebih mendasar terhadap melemahnya kurs rupiah, disebabkan yaitu:

Pertama, Neraca Perdagangan Barang \& Jasa menunjukkan kecenderungan defisit, yaitu ditunjukkan semakin melemahnya peranan ekspor tetapi sebaliknya terdapat peningkatan yang tajam akan barang dan jasa impor. Adapun macam barang yang diekspor adalah bahan mentah atau setengah jadi, sedang sebaliknya impor tidak saja berupa bahan baku bahkan berupa barang jadi yang sangat pokok sebagai konsumsi primer. Hal ini nampak pada awal kejatuhan rupiah, harga barang impor naik seiring dengan naiknya kurs mata uang asing, seharusnya kondisi ini membuat turunnya impor. Kenyataannya impor tidak berkurang, hal ini menunjukkan betapa seriusnya ketergantungan bangsa ini terhadap barang impor. Yang lebih ironi, justru ekspor menurun tajam akibat jatuhnya kurs rupiah karena:

- barang yang diekspor berbahan baku impor

- tingginya biaya modal sebab menggunakan kredit luar negeri tuntutan naiknya upah/gaji karyawan

Kesemuanya ini mengakibatkan naiknya biaya produksi atau membuat tingginya harga jual. Dampak berikutnya, yaitu menjadi semakin lemahnya penetrasi ekspor dalam persaingan perdagangan internasional. Kondisi ini membuat para investor menutup usahanya atau memindahkan usahanya ke luar negeri.

Kedua, Kecenderungan Surplus Neraca Modal. Surplus modal, dikarenakan antara lain:

- Beban pembayaran bunga dan cicilan hutang luar negeri, yang kian lama meningkat sangat pesatnya, baik oleh pemerintah maupun swasta.

- Keluarnya investor asing dari Indonesia, karena semakin tidak konduksifnya Iklim investasi dalam negeri.

- Pelarian modal dalam negeri, baik alasan ekonomi ataupun non ekonomi.

Selain depresiasi rupiah, kondisi perekonomian diperparah dengan meningkatnya suku bunga perbankan yang tinggi. Lembaga perbankan yang diharapkan sebagai agen pembangunan, yaitu diberlakukannya berbagai deregulasi untuk mempercepat akselerasi pertumbuhan, justru di sektor inilah terdapat penyimpangan kepercayaan dengan munculnya ketidakefisienan yang memicu krisis perekonomian yang akut.

Hasil uji kausalitas antara Kurs dan Tingkat Bunga, menggambarkan kronologis hubungan, sebagai berikut:

\section{Kurs mempengaruhi Tingkat Bunga atau sebaliknya.}

Depresiasi rupiah akhir Agustus 1997 atau apresiasi dollar US, berdampak sangat berat bagi kondisi perekonomian Indonesia dengan Neraca Perdagangan defisit dan Neraca Modal yang surplus. Supply rupiah yang sangat besar atau timbulnya permintaan dollar US yang tinggi, membuat rupiah mengalami depresiasi yang berat atau sebaliknya terjadi apresiasi dollar US yang tinggi. Situasi ini banyak dimanfaatkan oleh 
para pemilik dana, daripada memiliki rupiah atau deposito di bank akan lebih menguntungkan diinvestasikan dalam mata uang asing (dollar). Sehingga terjadilah penarikan besar-besaran dana masyarakat di bank, akibatnya perbankan dalam usaha menghimpun kembali dana tersebut dengan menaikkan tingkat bunga. Jatuhnya kurs rupiah diikuti naiknya tingkat bunga. Karena lembaga perbankan yang tidak efisien dan kepercayaan masyarakat yang semakin berkurang, dengan semakin tingginya tingkat bunga justru membuat penarikan dana yang semakin besar untuk dialihkan ke dollar. Permintaan dollar yang tinggi, menjadikan depresiasi rupiah semakin terpuruk. Hal ini berlangsung sampai puncaknya, kemudian situasi stabil dan hubungan Kurs dan Tingkat Bunga tetap saling mempengaruhi.

Dengan pengalaman krisis perekonomian ini, selain memperkuat sektor riil dan sektor moneter dalam negeri dalam era globalisasi, perlu dikaji kebijakan perekonomian yang dapat menangkal dampak negatif perekonomian luar negeri.

\section{DAFTAR PUSTAKA}

Arief, Sritua, 1993. Metodologi Penelitian Ekonomi, Jakarta: UI-PRESS.

Boediono, 1998. "Merenungkan Kembali Mekanisme Transmisi Moneter di Indonesia", Buletin Ekonomi dan Perbankan, Vol. I, No. 1, Juli, hal 1-4.

Dornbusch, Rudiger, 1983. "Real Interest Rate, Home Goods, and Optimal External Borrowing", Journal of Political Economy, Vol 91, No.1, , p.p. 141-153, the University of Chicago

Evans, Paul, 1986. "Is the Dollar High Because of the Large Budget Deficits",
Journal of Monetary Economic, 18, , p.p. $227-249$, North-Holland.

Frenkel, J.A., 1976. "A Monetary Approach to the Exchange Rate :Doctrinal Aspects and Empirical Evidence", Scandinavian Journal of Economics, No.2, May, p.p. $200-223$

Friedman, Milton, 1968. "The Role of Monetary Policy", The American Economic Review, Vol.LVIII, No. 1, March, pp. 1 - 17.

Granger, CWJ, 1969. "Investigating Causal Relations by Econometric Models and Cross-Spectral Methods", Econometrica, July, pp. 424-438

Gujarati, Damodar N, 2003. Basic Econometrics, Fourth Edition, Mc.Graw Hill, International Edition.

Hutchinson, M, \& Pigott, C, 1984. Budget Deficits, Exchange Rates and the Current Account: Theory and US Evidence, Federal Reserve Bank of San Francisco, Fall, No.4, p.p. 5 - 25

Mundell, RA, 1963. "Capital Mobility and Stabilization Policy Under Fixed and Flexible Exchange Rates", Canadian Journal of Economics and Political Science, Vol.XXIX, No.4, November, pp. $475-485$

Musa, Michael, 1974. "A Monetary Approach to Balance of Payment Analysis", Journal of Money Credit and Banking", Vol.6, , pp. 333 -351, USA 